Sensors 2003, 3, 443-450

sensors

ISSN 1424-8220

(C) 2003 by MDPI

http://www.mdpi.net/sensors

\title{
Determination of Dopamine in the Presence of Ascorbic Acid using Poly (Acridine red) Modified Glassy Carbon Electrode
}

\author{
Yuzhong Zhang*, Guiying Jin, Yanling Wang and Zhousheng Yang \\ School of Chemistry and Materials Science, Anhui Normal University, Wuhu 241000, China \\ *Author to whom correspondence should be addressed: zhangyz65@ hotmail.com
}

Received: 6 August 2003 / Accepted: 25 Septemeber 2003 / Published: 31 October 2003

\begin{abstract}
Poly (acridine red) modified glassy carbon electrode was used for the detection of dopamine in the presence of ascorbic acid in a $\mathrm{pH} 7.4$ phosphate buffer solutions (PBS) by cyclic voltammetry and differential pulse voltammetry. The major difficulty of the overlapped oxidation potential of ascorbic acid could be overcome through the distinct attractive ability of poly (acridine red) film to cationic dopamine and anionic ascorbic acid. The results showed that the dopamine anodic peak current and the concentration of dopamine had a linear relationship in the range of $1.0 \times 10^{-7} \sim 1.0 \times 10^{-4} \mathrm{~mol} \mathrm{dm}^{-3}$. The detection limit $(\mathrm{S} / \mathrm{N}=3)$ obtained by differential pulse voltammetry was $1.0 \times 10^{-9} \mathrm{~mol} \mathrm{dm}^{-3}$. The relative standard deviation of 10 successive scans was $2.07 \%$ for $1.0 \times 10^{-6} \mathrm{~mol} \mathrm{dm}^{-3}$ DA. Ascorbic acid had hardly interference with the determination of dopamine. The proposed method exhibits good recovery and reproducibility.
\end{abstract}

Keywords: Glassy carbon electrode; Chemically Modified electrode; Dopamine; Ascorbic Acid; Acridine red

\section{Introduction}

Dopamine (DA) is a kind of neurotransmitter in mammalian central nervous system. Extreme abnormalities of DA levels are symptoms of several diseases such as parkinsonism. So DA is currently the subject of intense research focus to neuroscientists and chemists and it is essential to develop rapid and simple methods for the determination of the concentration of DA. DA can be determined by electrochemical methods because it is an electrochemically active compound. However, a major problem encountered in the detection is the interference from ascorbic acid (AA), because AA largely 
coexists with DA in brain issue, therefor it is very difficult to determine DA directly. As we known, DA exists as a cation and AA exists as an anion at physiological $\mathrm{pH}$ 7.4. It is a possible way to overcome this problem by coating the electrodes with a thin film of Nafion [1-3] usually suffer from a slow response due to low diffusion coefficients [4-5] of analytes in the films. In order to overcome this problem, double - layer film [6-9] modified electrodes are used, which are coated first with an electroactive material having catalytic effect on the oxidation of DA and then with a Nafion layer.

In recent years, polymer-modified electrodes have attracted a great attention as polymeric film has good stability and reproducibility [10-11]. A number of researchers have employed polymeric film modified electrode to detect DA. So far, different methodologies have been used for depositing polymeric films. Electropolymerization is a good approach to immobilize polymers, because adjusting the electrochemical parameters can control film thickness, permeation and charge transport characteristics.

In the present work, we applied acridine red as a modifier to fabricate a poly (acridine red) modified glassy carbon electrode by electropolymerization method. The modified electrodes showed an electrocatalytic activity for the oxidation of DA. AA had no obvious response at this modified electrode. It is said the existence of AA did not interfere with the determination of DA. Hence the modified electrode can be used to detect DA in the high presence of AA at physiological $\mathrm{pH}$.

\section{Experimental}

\section{Reagents}

Acridine red was obtained from Shanghai Reagent Company (China). Dopamine and ascorbic acid were purchased from ICN Biomedicals Inc (USA). They and all the other chemical reagents are of analytical-reagent grade. PBS was prepared by $0.1 \mathrm{~mol} \mathrm{dm}{ }^{-3} \mathrm{KH}_{2} \mathrm{PO}_{4}-\mathrm{K}_{2} \mathrm{HPO}_{4}+0.1 \mathrm{~mol} \mathrm{dm}^{-3} \mathrm{NaCl}$, and adjusting the $\mathrm{pH}$ with $0.1 \mathrm{~mol} \mathrm{dm}^{-3} \mathrm{H}_{3} \mathrm{PO}_{4}$ and $0.1 \mathrm{~mol} \mathrm{dm}{ }^{-3} \mathrm{NaOH}$. All aqueous solutions were prepared in double distilled, de-ionized water.

\section{Apparatus}

A CHI 660A Electrochemical Workstation (CHI Instruments, Chenhua Corp, Shanghai, China) was used for electrochemical measurements. A conventional three-electrode system was employed with a bare or poly (acridine red) modified electrode (3.0 $\mathrm{mm}$ in diameter) as the working electrode, a saturated calomel electrode (SCE) as the reference electrode, and a platinum electrode as the counter electrode. All potentials reported in this paper were referenced to the SCE.

\section{Procedures}

The bare glassy carbon electrode (GCE) was polished successively with 0.3 and $0.05 \mu \mathrm{m} \mathrm{Al}_{2} \mathrm{O}_{3}$ slurry on emery paper before modification. Then it was rinsed with double distill water, and sonicated in 1:1 $\mathrm{HNO}_{3}$, acetone and double distilled water for $10 \mathrm{~min}$, respectively. After cleaning, the electrode was disposed by cyclic sweeping from -1.0 to $+2.5 \mathrm{~V}$ at $100 \mathrm{mV} \mathrm{s}^{-1}$ for 10 circles in $\mathrm{pH} 7.4 \mathrm{PBS}$ containing $1.0 \times 10^{-4} \mathrm{~mol} \mathrm{dm}^{-3}$ acridine red solution. 
All measurements were performed in a $10 \mathrm{~cm}^{3}$ electrolytic cell with $5 \mathrm{~cm}^{3}$ solutions, from which oxygen was removed by purging with high-purity nitrogen for $10 \mathrm{~min}$. All measurements were carried out under a nitrogen atmosphere.

\section{Results and Discussion}

Electropolymerization of Acridine Red at the GCE Surface

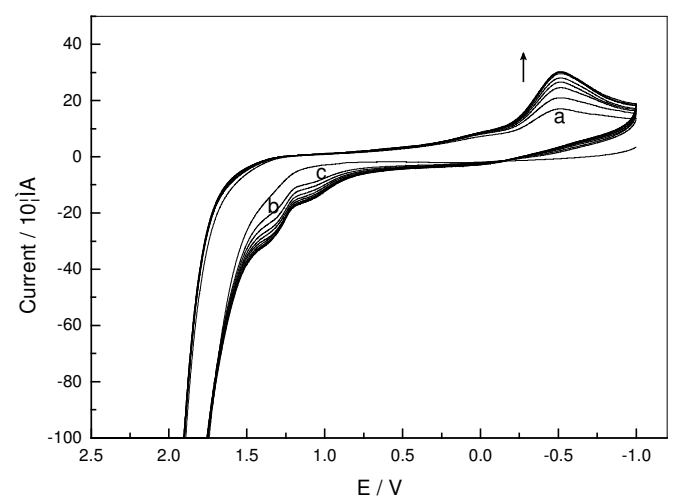

Figure 1. Repetitive cyclic voltammograms of $1.0 \times 10^{-4} \mathrm{~mol} \mathrm{dm}^{-3}$ acridine red in $\mathrm{pH} 7.4 \mathrm{PBS}$ solution; Terminal potential: $+2.5 \mathrm{~V}$; Initial potential: $-1.0 \mathrm{~V}$; Sensitivity: $1.0 \times 10^{-4} \mathrm{~A} / \mathrm{V}$; Scan rate: $100 \mathrm{mV} / \mathrm{s}$.

Cyclic voltammetry was used to form the acridine red film. Fig.1 shows voltammograms of $1.0 \times 10^{-4} \mathrm{~mol} \mathrm{dm}^{-3}$ acridine red in PBS ( $\mathrm{pH}=7.4$ ) over the potential range from $-1.0 \mathrm{~V}$ to $+2.5 \mathrm{~V}$ at the glassy carbon electrode. In the first potential scan, a cathodic peak (a) was observed near a potential value of $-0.52 \mathrm{~V}$. Oxidation peak was hardly observed. From the second cycle on, two obvious anodic peaks $(b, c)$ appeared, larger peaks were observed upon continuous scanning. These facts indicated acridine red was deposited on the surface of GCE by electropolymerization mode. It can be observed that film growth was faster in the six cycles. From the seventh cycle, the film was no longer growth. A uniform adherent carmine polymer film was formed on the GCE surface during electropolymerization. After modification, the poly (acridine red) film electrode was carefully rinsed with doubly distilled water, then storage in air and was prepared to use later.

\section{Cyclic Voltammograms of DA at Bare and Modified Electrodes}

Figure 2 shows cyclic voltammograms of DA at a bare glassy carbon electrode (GCE) and at a poly (acridine red) modified GCE. At the bare glassy carbon electrode (Fig.2a), DA exhibited a poor electrochemical response. The peak difference $\left(\Delta \mathrm{E}_{\mathrm{p}}\right)$ between anodic peak potential $\left(\mathrm{E}_{\mathrm{pa}}\right)$ and the cathodic potential $\left(\mathrm{E}_{\mathrm{pc}}\right)$ was $465 \mathrm{mV}$, but at the poly (acridine red) modified electrode, two couples of redox peaks were raised. Peak 1 and peak 2 was a couple of redox peak, which peak potential difference $\left(\Delta \mathrm{E}_{\mathrm{p}}\right)$ was $58 \mathrm{mV}$. It could be observed that oxidation peak potential of DA shifted negatively from $365 \mathrm{mV}$ (bare glass carbon electrode) to $136 \mathrm{mV}$ (modified electrode) and the overpotential decreased $229 \mathrm{mV}$. The oxidation current of DA (peak 1) at the modified electrode was 
more 50 times than that of DA at the bare GCE. These results indicated that poly (acridine red) film could accelerate the rate of electron transfer of DA in pH 7.4 PBS. We have employed hippuric acid [12], 2-picolinic acid [13] as modifier to fabricat modified electrode to detect DA in the presence of AA.
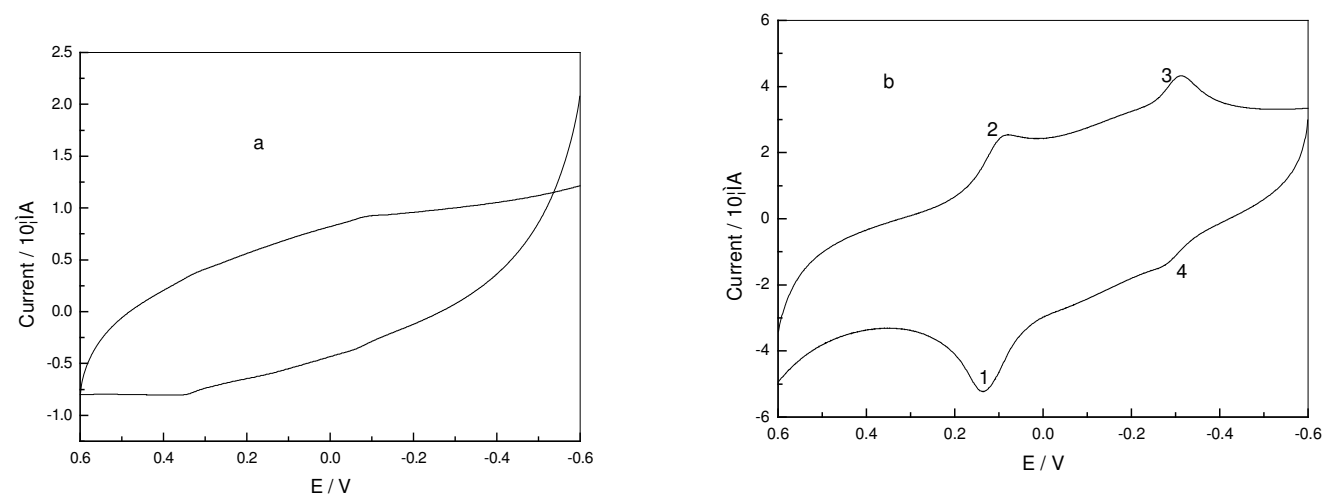

Figure 2. Cyclic voltammograms of $1.0 \times 10^{-4} \mathrm{~mol} / \mathrm{L} \mathrm{DA}$ in $\mathrm{pH} 7.4 \mathrm{PBS}$. (a) At the bare electrode, (b) At the modified electrode. Sensitivity: $1.0 \times 10^{-4} \mathrm{~A} / \mathrm{V}$. Scan rate: $100 \mathrm{mV} / \mathrm{s}$.

At hippuric acid or 2-picolinic acid modified electrode, DA exhibited two cathodic and one anodic peak. However at poly (acridine red) modified electrode. DA exhibited two couples of redox peaks. Reference [14] has clearly explained the mechanism of peak 1, peak 2 and peak 3. To establish the existence of peak 4 , we successively repeated the cyclic voltammograms of $1.0 \times 10^{-4} \mathrm{~mol} \mathrm{dm}^{-3} \mathrm{DA}$ in PBS of pH 7.4. As is shown in Fig.3.

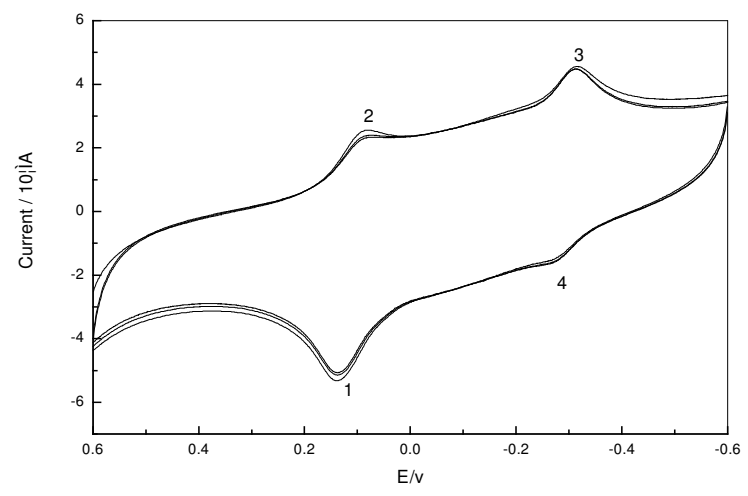

Figure 3. Repeated cyciic votammograms (6 scans) of $1.0 \times 10^{-4} \mathrm{~mol} / \bar{L} \mathrm{D} \dot{\mathrm{A}}$ in $\mathrm{PBS}$ of PH 7.4 at the poly (acridine red) film modified electrode. Sensitivity: $1.0 \times 10^{-4} \mathrm{~A} / \mathrm{V}$. Scan rate: $100 \mathrm{mV} / \mathrm{s}$.

From Fig.3, it can be found that peak 4 still appears as the scan increasing. According to reference [15-16] we thought peak 4 was corresponding to the oxidation of leucodopachrome (C) to dopachrome (D). The reason of it was as follows: 

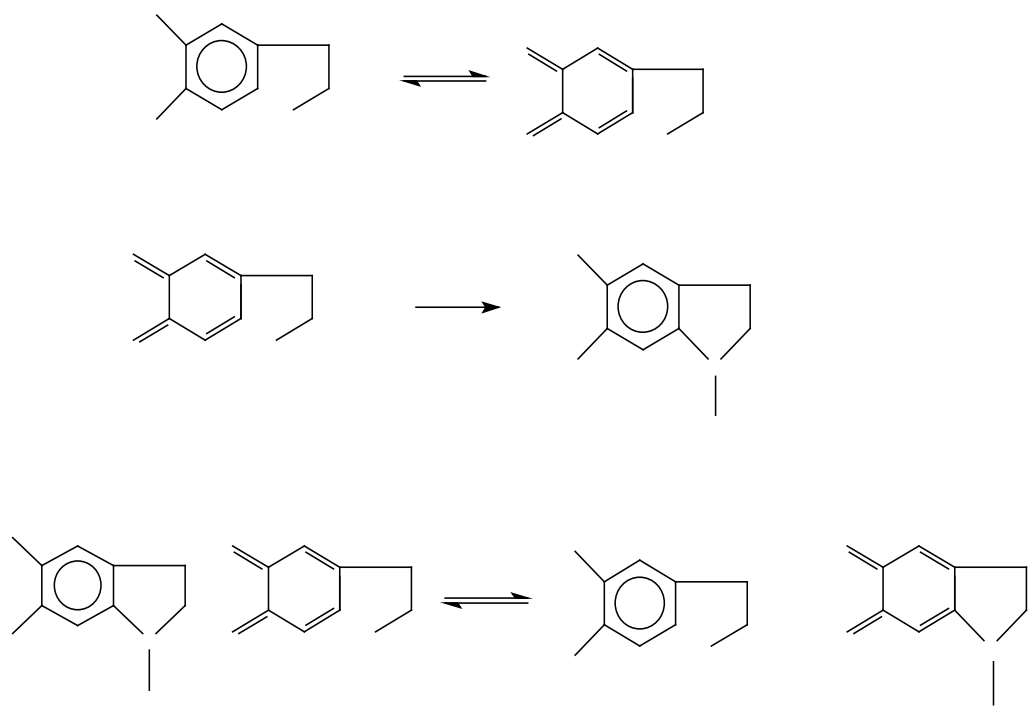

(A) Dopamine; (B) Dopaminequinone; (C) Leucodopachrome; (D) Dopachrome

In addition, the effect of the scan rate on the anodic peak current of DA was investigated. The $\mathrm{i}_{\mathrm{p}}$ was proportional to the square root of scan rate over the range of $40 \sim 220 \mathrm{mV} \mathrm{s}^{-1}$. The linear regression equation was $i_{p}(\mu \mathrm{A})=-1.11253+0.71948 \mathrm{v}^{1 / 2}\left(\mathrm{mV} \mathrm{s}^{-1}\right)^{1 / 2}$, with a correlation coefficient of $\mathrm{R}=0.9977$. So the electrode process was controlled-diffusion.

\section{Effect of Solution $\mathrm{pH}$}

The effect of solution $\mathrm{pH}$ on the response of DA was investigated over the range of $3 \sim 10$.
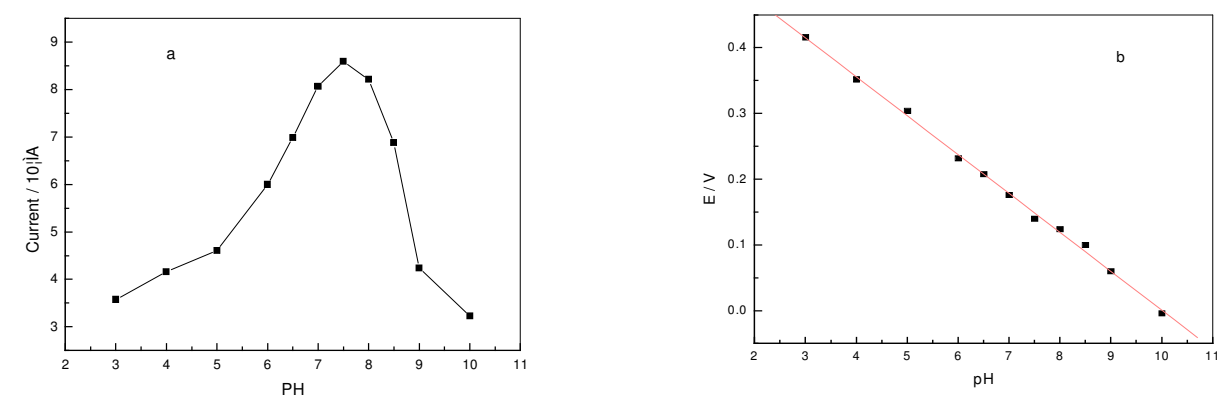

Figure 4. Effects of solution $\mathrm{pH}$ at the modified electrode on the cyclic voltammetric response of $1.0 \times 10^{-4} \mathrm{~mol} / \mathrm{L}$ DA. Sensitivity: $1.0 \times 10^{-4} \mathrm{~A} / \mathrm{V}$. Scan rate: $100 \mathrm{mV} / \mathrm{s}$. (a)Effects of solution $\mathrm{pH}$ on the current. (b) Effects of solution $\mathrm{pH}$ on the potential. 
Figure.4a shows that the anodic peak current increased with the increasing of solution $\mathrm{pH}$ until it reached 7.5. Then the anodic peak current decreased with increasing $\mathrm{pH}$. Since it was the physiological conditions, pH 7.4 was chosen in this paper.

Figure.4b shows that the relationship between anodic peak potential $\left(\mathrm{E}_{\mathrm{pa}}\right)$ of $\mathrm{DA}$ and $\mathrm{PH}$ of PBS solution. It can be found that $\mathrm{E}_{\mathrm{pa}}$ decreased with the increasing of solution $\mathrm{pH}$. The $\mathrm{E}_{\mathrm{pa}}$ is proportional to the $\mathrm{pH}$ over the range of $3 \sim 10$. The linear regression equation is $\mathrm{E}_{\mathrm{pa}}(\mathrm{V})=0.59243$ $0.05918 \mathrm{pH}$, with a correlation coefficient of $\mathrm{R}=-0.9990$. The slope is $59 \mathrm{mV}$. It indicates two electrons transfer following two protons transfer.

\section{Determination of DA}

The determination of DA concentration at the poly (acridine red) modified electrode was performed with differential pulse voltammetry. The oxidation peak current of DA was selected as the analytical signal. The results showed that anodic peak current was proportional to the concentration over the range of $1.0 \times 10^{-7} \sim 1.0 \times 10^{-4} \mathrm{~mol} \mathrm{dm}^{-3}$. The linear regression equation is $\mathrm{i}_{\mathrm{p}}(\mu \mathrm{A})=1.16006+0.43907 \mathrm{C}\left(\mu \mathrm{mol} \mathrm{dm}{ }^{-3}\right)$, with a correlation coefficient of $\mathrm{r}=0.9981$. The detection limit $(\mathrm{S} / \mathrm{N}=3)$ was $1.0 \times 10^{-9} \mathrm{~mol} \mathrm{dm}^{-3}$. The $\mathrm{r}$ elative standard deviation of 10 successive scans was $2.07 \%$ for $1.0 \times 10^{-6} \mathrm{~mol} \mathrm{dm}^{-3} \mathrm{DA}$, indicating excellent reproducibility of modified electrode.

Furthermore, we also investigated the stability of the poly (acridine red) modified electrode. The peak current could hardly change after storage in air for at least 3 weeks or cyclically scanned in PBS solution.

\section{Interference Study}

Ascorbic acid (AA) coexists with DA in the extracellular fluid of the central nervous systems and its concentration $\left(10^{-4} \mathrm{~mol} \mathrm{dm}^{-3}\right)$ is much higher than that of DA $\left(10^{-8} \sim 10^{-6} \mathrm{~mol} \mathrm{dm}^{-3}\right)$. We can use the anodic peak potential for DA detection to eliminate the interference of AA. Since differential pulse voltammetry can improve the selectivity and sensitivity of the determination. So we used it to study the interference of AA and other compounds.

Fig.5 shows differential pulse voltammograms obtained at the polymer modified electrode. Fig. $5 \mathrm{~A}(1)$ was recorded in $1.0 \times 10^{-2} \mathrm{~mol} \mathrm{dm}{ }^{-3}$ AA solution. Fig. $5 \mathrm{~A}(2)$ was recorded in $1.0 \times 10^{-4} \mathrm{~mol}$ $\mathrm{dm}^{-3}$ DA solution. Fig.5 A(3) was recorded in a solution containing $1.0 \times 10^{-4} \mathrm{~mol} \mathrm{dm}^{-3} \mathrm{DA}$ and $1.0 \times 10^{-}$ ${ }^{2} \mathrm{~mol} \mathrm{dm}{ }^{-3} \mathrm{AA}$. The anodic peak current of DA was not obvious change in presence of high ascorbic acid, which indicted that $1.0 \times 10^{-2} \mathrm{~mol} \mathrm{dm}^{-3} \mathrm{AA}$ didn $\mathrm{t}$ interfere with the determination of $1.0 \times 10^{-4} \mathrm{~mol}$ $\mathrm{dm}^{-3}$ DA. Fig.5B shows different DA concentration differential pulse voltammograms at modified electrode in the presence of $1.0 \times 10^{-2}$ mol dm${ }^{-3}$ AA. Fig. $5 \mathrm{~B}$ (a) was recorded in $1.0 \times 10^{-2} \mathrm{~mol} \mathrm{dm}^{-3}$ AA, Fig.5 B(b) was recorded in $1.0 \times 10^{-4} \mathrm{~mol} \mathrm{dm}^{-3} \mathrm{DA}$ and $1.0 \times 10^{-2} \mathrm{~mol} \mathrm{dm}^{-3}$ AA. The anodic peak current of DA was increased as DA concentration increased in the presence of AA (Fig.5 B (b) to Fig.5 B (e)). We can observe no less than 100 times AA had no interference with the determination of DA. AA only had a very poor response at $0.000 \mathrm{~V}$ at the modified electrode. The anodic current and potential of DA had no change with the increasing concentration of AA from the Fig.5. It entirely eliminated the interference of AA. The facts indicated DA could be determined in the presence pf high AA 
concentration using poly (acridine red) film modified electrode. The reason for these is as follows: DA exists in the cationic form in PBS solution of $\mathrm{pH}$ 7.4. The polymeric film exists in a negative charge. Hence, in contrast, AA exists in the anionic form in PBS solution of $\mathrm{pH}$ 7.4. The negative charge polymeric film repels it. So it cannot enter the polymer film to the sane extent as DA. And the interference with the determination of DA is diminished.
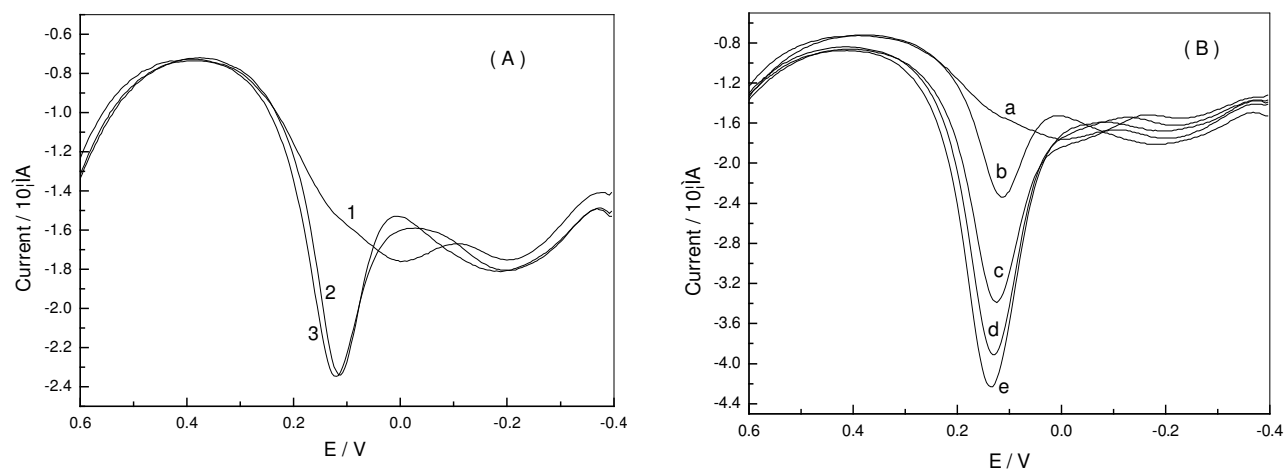

Figure 5(A). Differential pulse voltammetric at the modified electrode in $\mathrm{pH} 7.4$ PBS (1): $1.0 \times 10^{-2} \mathrm{~mol}$ $\mathrm{dm}^{-3} \mathrm{AA}$; (2): $1.0 \times 10^{-4} \mathrm{~mol} \mathrm{dm}{ }^{-3} \mathrm{DA}$; (3): $1.0 \times 10^{-2} \mathrm{~mol} \mathrm{dm}^{-3} \mathrm{AA}+1.0 \times 10^{-4} \mathrm{~mol} \mathrm{dm}^{-3} \mathrm{DA}$

Figure 5(B). DPV recordings of DA at modified electrode and in the presence of $1.0 \times 10^{-2} \mathrm{~mol} \mathrm{dm}^{-3}$ AA in pH 7.4 PBS. DA concentration $\left(10^{-4} \mathrm{~mol} \mathrm{dm}^{-3}\right)$ : (a) 0 (b) 1.0 (c) 2.0 (d) 3.0 (e) 4.0

Parameter: Amplitude: $50 \mathrm{mV}$; Pulse Width: $50 \mathrm{~ms}$; Pulse Period: $200 \mathrm{~ms}$;Sensitivity: $2.0 \times 10^{-5} \mathrm{~A} / \mathrm{V}$

We also studied interference of other compounds. To $1.0 \times 10^{-4} \mathrm{~mol} \mathrm{dm}^{-3} \mathrm{DA}$, the following compounds had no interference: hippuric acid (100), citric acid (50), cysteine (50), glucose (100), $\mathrm{NaCl}$ (300), $\mathrm{KCl}$ (300), $\mathrm{CaCl}_{2}$ (100).

\section{Analytical Applications}

The injection of DA was analyzed by the standard addition method. The results are shown in Table 1. It is accordant with the result by the China Pharmacopoeia method [17], showing that the proposed methods could be efficiently used for the determination of DA in injection.

Table 1. Results of DA analysis in injections $(n=10)$

\begin{tabular}{|c|c|c|c|c|c|}
\hline Sample & $\begin{array}{l}\text { Content } \\
10^{-5} \mathrm{~mol} \mathrm{dm}^{-3}\end{array}$ & $\begin{array}{l}\text { Found } \\
10^{-5} \mathrm{~mol} \mathrm{dm}^{-3}\end{array}$ & $\begin{array}{l}\text { RSD } \\
\%\end{array}$ & $\begin{array}{l}\text { Recovery } \\
\%\end{array}$ & $\begin{array}{l}\text { Pharmacopeia Method } \\
10^{-5} \mathrm{~mol} \mathrm{dm}^{-3}\end{array}$ \\
\hline 1 & 1.0 & 0.97 & 2.9 & 97 & 1.01 \\
\hline 2 & 1.0 & 1.01 & 2.0 & 101 & 1.04 \\
\hline 3 & 1.0 & 1.03 & 2.7 & 103 & 1.05 \\
\hline 4 & 1.0 & 0.99 & 3.2 & 99 & 1.02 \\
\hline 5 & 1.0 & 0.98 & 2.2 & 98 & 1.02 \\
\hline
\end{tabular}




\section{Conclusions}

The results obtained show poly (acridine red) film modified electrode can promote DA oxidation. Peak current of DA was proportional to the concentration over the range of $1.0 \times 10^{-7}$ $\sim 1.0 \times 10^{-4} \mathrm{~mol} \mathrm{dm}^{-3}$ with a detection limit $(\mathrm{S} / \mathrm{N}=3)$ of $1.0 \times 10^{-9} \mathrm{~mol} \mathrm{dm}^{-3}$. The results of differential pulse voltammetry show that the interference of AA was entirely eliminated in determination of DA in pH 7.4 PBS. And proposed methods can be applied to the detection of DA in samples.

\section{References}

1. Kawage, T. K.; Wightman, R. M. Talanta, 1994, 41, 865.

2. Gerhardt, G. A.; Oke, A. F.; Nagy, G.; Moghaddam, B.; Adams, R. N.; Brain Research, 1984, 290,390 .

3. Nagy, G.; Gerhardt, G. A.; Oke, A. F.; Rice, M. E.; Adams, R. N. J.Electroanal. Chem, 1985, 188, 85.

4. Wang, J.; Peng, T. Z. Anal. Chem, 1986, 58,3257.

5. Guadalupe, A. R.; Abruna, H. D. Anal. Chem, 1985, 57, 142.

6. Zen, J. M.; Chen, I. L. Electroanalysis, 1997, 9, 537.

7. Kang, T. F.; Shen, G. L.; Yu, R. Q. Anal. Chim. Acta, 1997,354,343.

8. Ju, H. X.; Mi, J. A.; Gong, Y.; Chen, H. Y.; Leech, D. Anal.Lett, 1999, 32, 2951.

9. Zhou, D. M.; Ju, H. X.; Chen, H. Y. J. Electroanal.Chem, 1996, 408, 219.

10. Sun, Y. X.; Ye, B. X.; Wang, Y.; Tang, X. R.; Zhou, X. Y. J. Microchemical, 1998, 58, 182.

11. Brett, C. M. A.; Inzelt, G.; Kertesz, V. Anal. Chim. Acta, 1999, 385 (1-3), 119.

12. Zhao, H.; Zhang, Y. Z.; Yuan, Z. B. Electroanalysis, 2002, 14 (14), 1031.

13. Zhao, H.; Zhang, Y. Z.; Yuan, Z. B. Analyst, 2001, 126, 358.

14. Zhao, H.; Zhang, Y. Z.; Yuan, Z. B. Electroanalysis, 2002, 6, 446.

15. Hawley, M. D.; Tatawawadi, S. V.; Piekarski, S.; Adams, R. N. J. Am. Chem. Soc, 1967,89,447.

16. Zhu, M.; Huang, X. M.; Li, J.; Shen, H. X. Anal. Chim. Acta, 1997,357,261.

17. Editorial Committee of Pharmacopoeia of People's Republic of China, People s Republic of China Pharmacopoeia 2000, Beijing, 2000, Vol.2, p592

Sample Availability: Available from the authors.

(C) 2003 by MDPI (http://www.mdpi.org). Reproduction is permitted for noncommercial purposes. 